\title{
APPLICATION OF AMIT JAIN'S SCORING SYSTEM IN DIABETIC FOOT AMPUTEES
}

\author{
Kalaivani $V^{1}$, Khyati Melanta ${ }^{2}$
}

${ }^{1}$ Associate Professor, Department of General Surgery, M. S. Ramaiah Hospital, Bangalore.

${ }^{2} 2^{\text {nd }}$ Year Post Graduate, General Surgery, M. S. Ramaiah Hospital, Bangalore.

\section{ABSTRACT}

\section{BACKGROUND}

Major amputation is an unfortunate outcome of diabetic foot complications. There was no way to assess the justification of major amputation or the risk associated for the major amputation.

\section{AIM}

To evaluate the suitability of Amit Jain's scoring in post-amputation cases done in diabetic foot between 2013 and 2015.

\section{METHODS}

A retrospective review of the records of all patients with diabetic foot complications, who underwent major lower limb amputation between 2013 and 2015 was performed. Patient's particulars and clinical findings were recorded and scored based on Amit Jain's scoring system and the patients were stratified into different risk groups.

\section{RESULTS}

A total of 21 patients with major amputation were included in this study. Majority of our patients were males. Below Knee Amputation (BKA) was the commonest amputation in our study accounting for $80.95 \%$ of the cases. Majority (85.7\%) of our cases were having type 1 diabetic foot complications with wet gangrene being the commonest cause of major amputation. Most patients in our study belonged equally to high risk and very high risk category of major amputation. From the results obtained in the study, we observed that $66 \%$ of the patients who underwent amputation belonged either to high or very high risk categories as per Amit Jain's Classification. This concordance with the classification validates the effectiveness of stratifying patients into various categories for deciding the need for amputation. There was no mortality in this study.

\section{CONCLUSION}

Our clinical assessment in diabetic foot patients was in concurrence with the recommendation of amputation as per the scoring system. Amit Jain's scoring system is a new and unique tool to predict amputation in patients with diabetic foot complications.

\section{KEYWORDS}

Diabetic Foot, Amit Jain, Scoring, Amputation.

HOW TO CITE THIS ARTICLE: Kalaivani V, Melanta K. Application of Amit Jain's scoring system in diabetic foot amputees. J. Evolution Med. Dent. Sci. 2016;5(28):1413-1417, DOI: 10.14260/jemds/2016/333

\section{INTRODUCTION}

The global prevalence of diabetes is predicted to be 366 million people by 2030.[1,2] Foot infection is considered to be the most common and feared complication of diabetes.[3] It is believed that $15 \%$ of all diabetic patients will develop some form of foot problems during their lifetime.[1,4] Foot ulcers carry a $25 \%$ risk of major lower extremity amputation.[4] In fact, the risk of amputation in diabetic patient is 10-30 times higher in comparison with general population. [5]

Recently, a new scoring system has been proposed by Amit Jain [Table 1] that predicts the risk of major amputation in diabetic foot complications.[6] We studied the risk of major amputation through the Amit Jain's classification system that studies diabetic foot in a different way, thereby creating a standard way of understanding and dealing with diabetic foot problems.

\section{AIM OF THE STUDY}

To evaluate the suitability of Amit Jain's criteria in postamputation cases between 2013 and 2015 .

Financial or Other, Competing Interest: None.

Submission 02-02-2016, Peer Review 01-03-2016,

Acceptance 07-03-2016, Published 05-04-2016.

Corresponding Author:

Dr. Khyati Melanta,

$364 / 1,12^{\text {th }}$ Cross, $5^{\text {th }}$ Main,

Dollars Colony, RMV 2nd Stage,

Bangalore-560094.

E-mail: kmelanta@gmail.com

DOI: $10.14260 /$ jemds/2016/333

\section{METHODS AND MATERIALS}

A retrospective review of the records of all patients with diabetic foot complications who underwent major lower limb amputation between 2013 and 2015 in M. S. Ramaiah Hospital was performed. Patients were identified using a computer generated search through the medical records department. Medical records were reviewed for the following: Age, gender, presence of diabetic foot complications and clinical findings as per Amit Jain's scoring system. Patients were scored and were stratified into different risk groups.

Major amputations done in other departments, major amputation done in diabetes patients due to trauma or malignancy and patients with poor data recording in the files/missing files were excluded.

\section{RESULTS}

Out of 32 cases, only 21 were included in this study. We excluded 11 patients in view of incomplete data in the files needed for this study.

The mean age of the study population was 56.76 years (SD 9.2). Seventeen patients [80.95\%] were males and 4 patients were females [19.05\%]. Mean age of females being 46.25 (SD 4.7), while that of males was 59.24 (SD 8.2).

The average score as per Amit Jain's scoring system was 15.72 (SD 5.4) for females and 22.47 (SD 4.73) for males [Figure 1]. The difference in mean score between men and women was found to be statistically significant $(\mathrm{p}<0.05)$ 
The right lower limb was involved in 11 cases [52.38\%] and left limb in 10 cases [47.62\%]. In 13 cases [61.91\%], the pathological lesions were confined to foot and in 8 cases [38.1\%] it extended beyond foot involving leg also.

Majority [80.95\%] of our patients [Table 2] had Below Knee Amputation (BKA). The ratio of BKA to above knee amputation was 4.25:1 in our series.

The commonest pathological lesion in our study was wet gangrene [Table 3] involving 11 patients [52.38\%] followed by abscess [28.57\%]. Out of 6 cases of abscess [Figure 2], 2 patients had presented to us with infected ulcer with purulent discharge. These patients were operated outside recently and they were primarily diagnosed as diabetic foot abscess in their discharge summary. Hence, we placed these infected wounds/ulcer in abscess category as they had short history and these cases had undergone inappropriate debridement.

The other 2 ulcer patients had prior history of nonhealing ulcer, which seemed to have got infected and hence these ulcers were chronic in nature. We had a total of 3 patients who had type 3 diabetic foot complications. The third patient had peripheral arterial disease with gangrene of toes and infected ulcer on the foot. The rest had type 1 diabetic foot complications.

From the results obtained in the study, we observed that $66 \%$ of the patients who underwent amputation belonged either to high [Figure 3 and 4] or very high risk categories as per Amit Jain's Classification [Table 4]. Four patients [19.05\%] belonged to category of inevitable amputation category. The lowest score in our study was 10 and the highest was 32 .

This concordance with the classification validates the effectiveness of stratifying patients into various categories for deciding the need for amputation. There was no mortality in this study.

\section{DISCUSSION}

Diabetic foot is known to have a major medical, social and economic consequence.[4] More than $50 \%$ of lower limb amputations are performed on diabetic patients.[7] Once amputation is performed, the patient has to stay longer in hospital and are at a risk of further complications, mortality and increased cost. Major amputations in diabetic foot are disfiguring operations that carry a high morbidity and mortality.[8] Lower limb amputations however are considered a last resort when salvage is not possible.[8]

There was never a tool to assess major amputations in diabetic foot performed by surgeons. Amit Jain's scoring system is probably the first and the only surgical scoring system till date.[6] Amit Jain's scoring system for diabetic foot is a newly formulated score, which appeared in literature in 2014.[6] There are not many studies validating this score.

Our study showed that major amputations were common in similar to Jain et al. series.[9] Below knee amputation was the commonest amputation in our series and also in Jain et al. series. ${ }^{[9]}$

The commonest cause for major amputation in this study was wet gangrene. In a study from Kenya. ${ }^{[10]}$ gangrene on the whole was a major cause for major and minor amputations.

Our study showed that majority of the patients belonged equally to very high risk and high risk for major amputations followed by inevitable amputation category. Around $85.7 \%$ of our patients had a score above 16 , whereas in Jain et al. series had a score more than 16 in $80 \%$ of patients. ${ }^{[9]}$

The Amit Jain scoring system clearly states that no major amputations should be done with score less than 5 and all patients who have a score above 26 will invariably require major amputation. ${ }^{6]}$

This affirmative statement would in future help us decide that patients having a score of more than 26 should not be unnecessarily investigated with higher imaging modalities/therapeutic salvage intervention. Only few more future studies would help us to determine the actual outcomes of higher scores.

We need to thoroughly understand this scoring system which has clinical, radiological and surgical factors determining an appropriate scoring. Inappropriate understanding and scoring wrongly could lead to inaccurate data. We believe that a prospective study would be more appropriate, as all the parameters would be recorded more appropriately and followed accordingly. Only hospitalized and operated diabetic foot patients could be studied by this scoring system, as operative data is essential to arrive at a final score for the patients. There were certain limitations in our study. First, our sample size was small. Further, there was a difficulty in obtaining data in view of weak case sheet recordings in some case files.

\section{CONCLUSION}

This scoring system serves us a reliable tool to study amputations performed by surgeons and also can be used to look at diabetic foot lesion prospectively and determining the risk category that they present to hospital. The score could also serve an important tool as a recording sheet of diabetic foot patients who underwent surgery.

\section{ACKNOWLEDGEMENTS}

We would like to thank Dr. B. S. Nanda Kumar, Head-Research and IPR, Division of Research and Patents and Associate Professor-Community Medicine, M. S. Ramaiah Medical College and Hospitals and Dr. K N Chidambaram Murthy, Chief Scientist, Central Research Laboratory, M. S. Ramaiah Hospital, for their support.

\begin{tabular}{|c|c|c|c|c|c|}
\hline $\begin{array}{c}\text { Sl. } \\
\text { No. }\end{array}$ & Characteristics & \multicolumn{4}{|c|}{ Involvement of Foot/Characteristics } \\
\hline 1. & Presence of ulcer & No ulcer $\rightarrow 0$ & Forefoot ulcer $\rightarrow 2$ & Midfoot ulcer $\rightarrow 4$ & Hindfoot ulcer/full foot $\rightarrow 6$ \\
\hline 2. & Osteomyelitis [O.M] & No O.M $\rightarrow 0$ & Forefoot O.M $\rightarrow 2$ & Midfoot O.M $\rightarrow 4$ & Hindfoot O.M $\rightarrow 6$ \\
\hline 3. & Presence of pus & No pus $\rightarrow 0$ & Forefoot pus/dorsum $\rightarrow 2$ & Midfoot pus $\rightarrow 4$ & Hindfoot pus/beyond it $\rightarrow 6$ \\
\hline 4. & Gangrene [dry/wet] & $\begin{array}{c}\text { No } \\
\text { gangrene } \rightarrow 0\end{array}$ & Forefoot gangrene $\rightarrow 2$ & $\begin{array}{c}\text { Midfoot gangrene } \\
\rightarrow 4\end{array}$ & $\begin{array}{c}\text { Hindfoot } \\
\text { gangrene/beyond } \rightarrow 8\end{array}$ \\
\hline 5. & $\begin{array}{c}\text { Peripheral arterial } \\
\text { disease [P.A.D] }\end{array}$ & No P.A.D $\rightarrow 0$ & Mild $\rightarrow 2$ & Moderate $\rightarrow 4$ & Severe $\rightarrow 8$ \\
\hline
\end{tabular}




\begin{tabular}{|c|c|c|c|c|c|}
\hline 6. & Charcot foot & $\mathrm{No} \rightarrow 0$ & Forefoot $\rightarrow 2$ & Midfoot $\rightarrow 4$ & Hindfoot/whole foot $\rightarrow 8$ \\
\hline 7. & Necrosis of the skin & No $\rightarrow 0$ & Forefoot necrosis $\rightarrow 2$ & $\begin{array}{l}\text { Midfoot necrosis } \\
\rightarrow 4\end{array}$ & $\begin{array}{c}\text { Hindfoot } \\
\text { necrosis/beyond } \rightarrow 8\end{array}$ \\
\hline 8. & Associated cellulitis & No $\rightarrow 0$ & Upto forefoot $\rightarrow 2$ & Upto midfoot $\rightarrow 4$ & Upto hindfoot \& beyond $\rightarrow 6$ \\
\hline 9. & Previous amputation & No $\rightarrow 0$ & Toe amputation $\rightarrow 2$ & $\begin{array}{c}\text { Forefoot } \\
\text { amputation } \rightarrow 4\end{array}$ & Midfoot amputation $\rightarrow 6$ \\
\hline 10. & $\begin{array}{l}\text { Presence of gas - } \\
\text { radiologically } \\
\end{array}$ & No $\rightarrow 0$ & Gas in forefoot $\rightarrow 1$ & $\begin{array}{l}\text { Gas in/upto } \\
\text { midfoot } \rightarrow 2\end{array}$ & Gas in/upto hindfoot $\rightarrow 3$ \\
\hline 11. & Myonecrosis & No $\rightarrow 0$ & $\begin{array}{l}\text { Myonecrosis involving } \\
\text { single muscle group } \rightarrow 2\end{array}$ & $\begin{array}{c}\text { Myonecrosis } \\
\text { involving more than } \\
\text { one group } \rightarrow 4\end{array}$ & $\begin{array}{c}\text { Myonecrosis of entire foot } \\
\text { muscle with extension to leg } \rightarrow 8\end{array}$ \\
\hline 12. & Joint involvement & No $\rightarrow 0$ & $\begin{array}{l}\text { Forefoot joint } \\
\text { exposure } \rightarrow 2\end{array}$ & $\begin{array}{l}\text { Midfoot joint } \\
\text { exposure } \rightarrow 4\end{array}$ & Hindfoot joint exposure $\rightarrow 6$ \\
\hline 13. & Septic shock & \multicolumn{2}{|r|}{ No $\rightarrow 0$} & \multicolumn{2}{|c|}{ Present $\rightarrow 2$} \\
\hline 14. & Renal failure & \multicolumn{2}{|r|}{ No $\rightarrow 0$} & \multicolumn{2}{|c|}{ Present $\rightarrow 2$} \\
\hline 15. & Smoking & \multicolumn{2}{|r|}{ No $\rightarrow 0$} & \multicolumn{2}{|c|}{ Present $\rightarrow 2$} \\
\hline 16. & Surgeon factor & \multicolumn{2}{|c|}{ Qualified diabetic foot specialist $\rightarrow 0$} & \multicolumn{2}{|c|}{ Other surgeons $\rightarrow 2$} \\
\hline \multicolumn{6}{|c|}{ Table 1: Showing the Amit Jain's Scoring System for Diabetic Foot Complications } \\
\hline
\end{tabular}

\begin{tabular}{|c|c|c|c|}
\hline $\begin{array}{l}\text { Sl. } \\
\text { No. }\end{array}$ & $\begin{array}{l}\text { Type of Major } \\
\text { Amputation }\end{array}$ & Number & Percentage \\
\hline 1. & Below knee amputation & 17 & $80.95 \%$ \\
\hline \multirow[t]{2}{*}{2.} & Above knee amputation & 04 & $19.05 \%$ \\
\hline & Total & 21 & $100 \%$ \\
\hline \multicolumn{4}{|c|}{$\begin{array}{l}\text { Table 2: Showing Distribution } \\
\text { of Cases of Major Amputation }\end{array}$} \\
\hline
\end{tabular}

\begin{tabular}{|c|c|c|c|}
\hline $\begin{array}{l}\text { Sl. } \\
\text { No. }\end{array}$ & Pathological Lesion & Number & Percentage \\
\hline 1. & Wet Gangrene & 11 & $52.38 \%$ \\
\hline 2. & Necrotizing Fasciitis & 2 & $9.52 \%$ \\
\hline 3. & $\begin{array}{c}\text { Infected Ulcer } \\
\text { [Chronic/Non-healing] }\end{array}$ & 2 & $9.52 \%$ \\
\hline \multirow[t]{2}{*}{4.} & Abscess & 6 & $28.57 \%$ \\
\hline & Total & 21 & $100 \%$ \\
\hline & $\begin{array}{r}\text { Table 3: Showing D } \\
\text { According to Pa } \\
\end{array}$ & $\begin{array}{l}\text { ribution } \\
\text { logical LC }\end{array}$ & $\begin{array}{l}\text { ases } \\
n\end{array}$ \\
\hline
\end{tabular}

\begin{tabular}{|c|c|c|c|}
\hline $\begin{array}{c}\text { Sl. } \\
\text { No. }\end{array}$ & Risk/Score & Number & Percentage \\
\hline $\mathbf{1 .}$ & Low Risk [6-10] & 1 & $4.76 \%$ \\
\hline $\mathbf{2 .}$ & Moderate Risk [11-15] & 2 & $9.52 \%$ \\
\hline $\mathbf{3 .}$ & High Risk [16-20] & 7 & $33.33 \%$ \\
\hline $\mathbf{4 .}$ & Very High Risk [21-25] & 7 & $33.33 \%$ \\
\hline $\mathbf{5 .}$ & Inevitable Amputation & 4 & $19.05 \%$ \\
\hline \multicolumn{3}{|c|}{ [ 26] } & Table 4: Showing Distribution of Cases \\
According to Amit Jain Scoring System \\
\hline
\end{tabular}

\begin{tabular}{|c|c|c|c|c|c|c|}
\hline & N & Range & Minimum & Maximum & Mean & $\begin{array}{c}\text { Std. } \\
\text { Deviation }\end{array}$ \\
\hline AGE & 21 & 35 & 40 & 75 & 56.76 & 9.224 \\
\hline SCORE & 21 & 22 & 10 & 32 & 21.19 & 5.446 \\
\hline $\begin{array}{c}\text { Valid N } \\
\text { Listwise) }\end{array}$ & 21 & \multicolumn{7}{|c|}{ Descriptive Statistics } \\
\hline \multicolumn{7}{|c|}{} \\
\hline
\end{tabular}

\begin{tabular}{|c|c|c|c|c|c|c|}
\hline & N & Range & Minimum & Maximum & Mean & $\begin{array}{c}\text { Std. } \\
\text { Deviation }\end{array}$ \\
\hline AGE & 4 & 10 & 40 & 50 & 46.25 & 4.787 \\
\hline SCORE & 4 & 13 & 10 & 23 & 15.75 & 5.439 \\
\hline $\begin{array}{c}\text { Valid N } \\
\text { (Listwise) }\end{array}$ & 4 & & & & & \\
\hline a. SEX = F & & & & \\
\hline \multicolumn{8}{|c|}{ Descriptive Statistics. ${ }^{\text {a }}$} \\
\hline
\end{tabular}
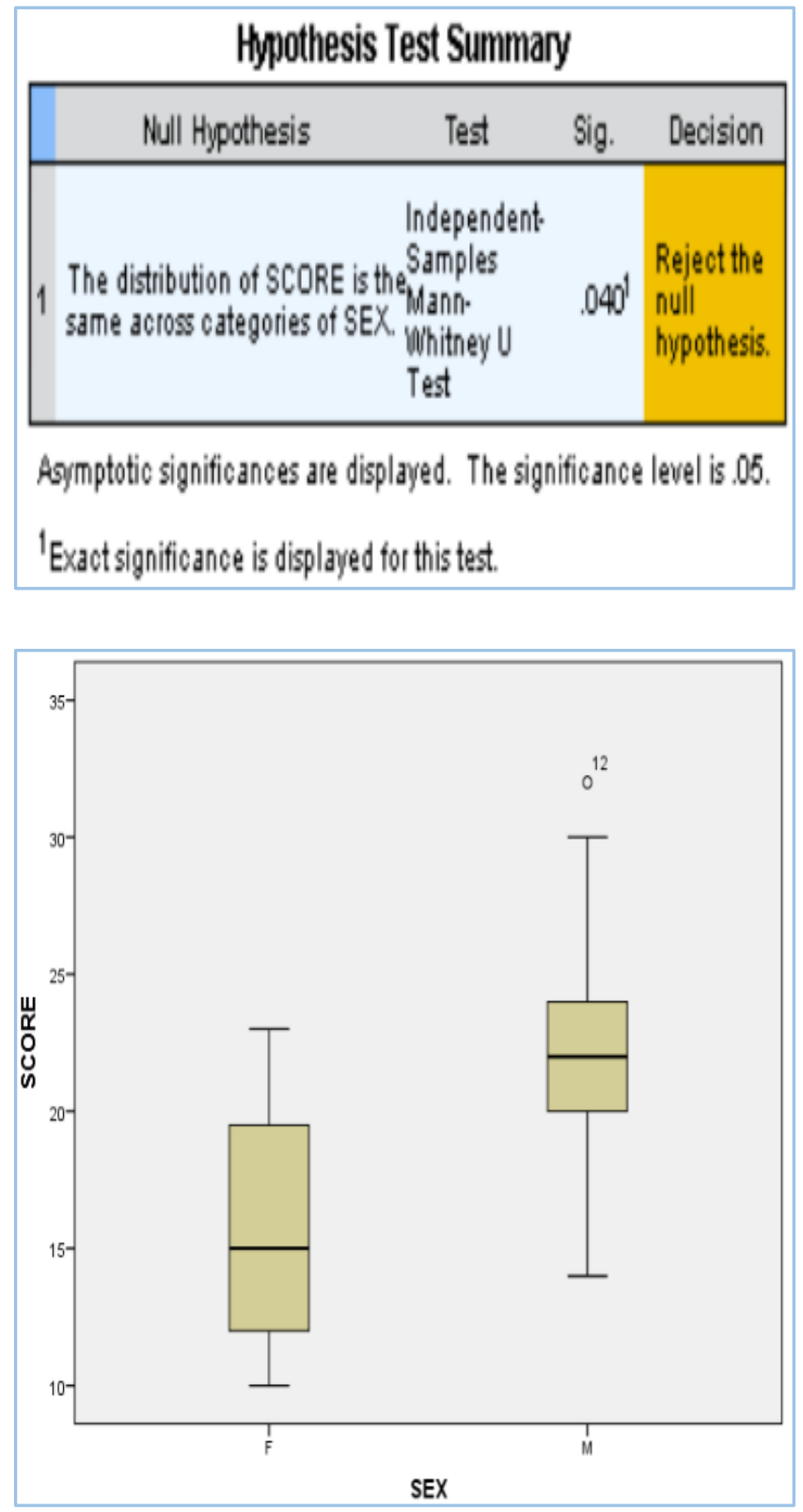

Fig. 1: Box Plot Depicting the Mean Scores between Males and Females 


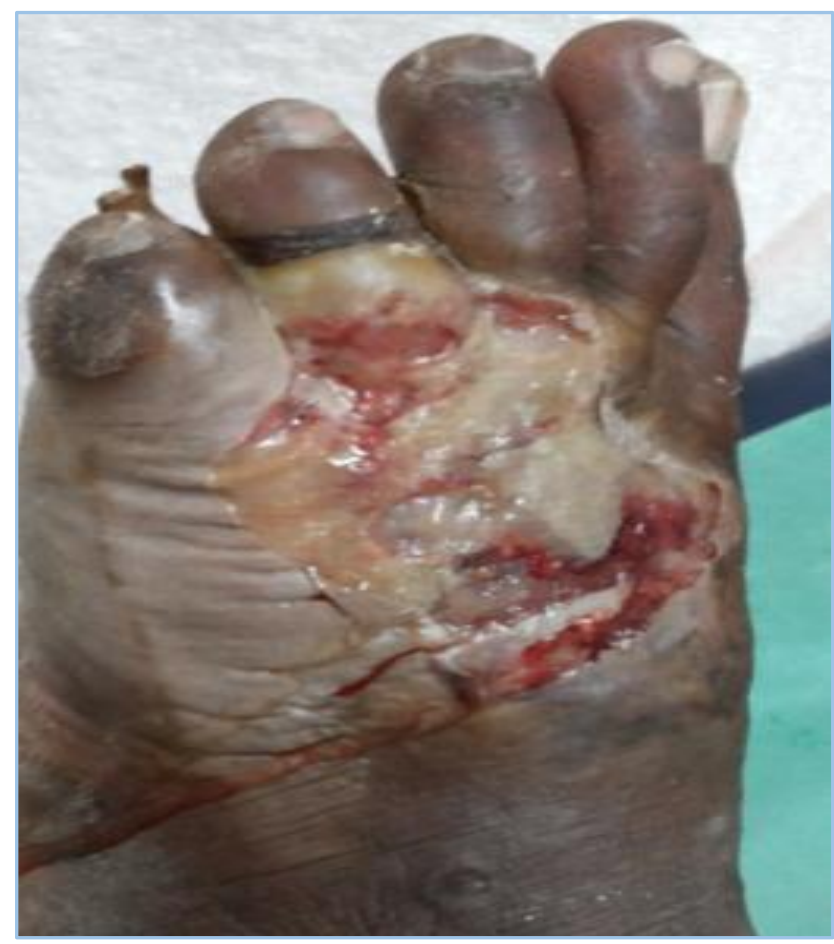

Fig. 2: Showing Abscess over Left Foot with Skin Necrosis after Deroofing the Blister [Dorsal View].

His Score was Pus 6 + Skin Necrosis 4 + Cellulitis 6 + Surgeon Factor 2. Total Score was 18 rendering him to High Risk for Major Amputation.

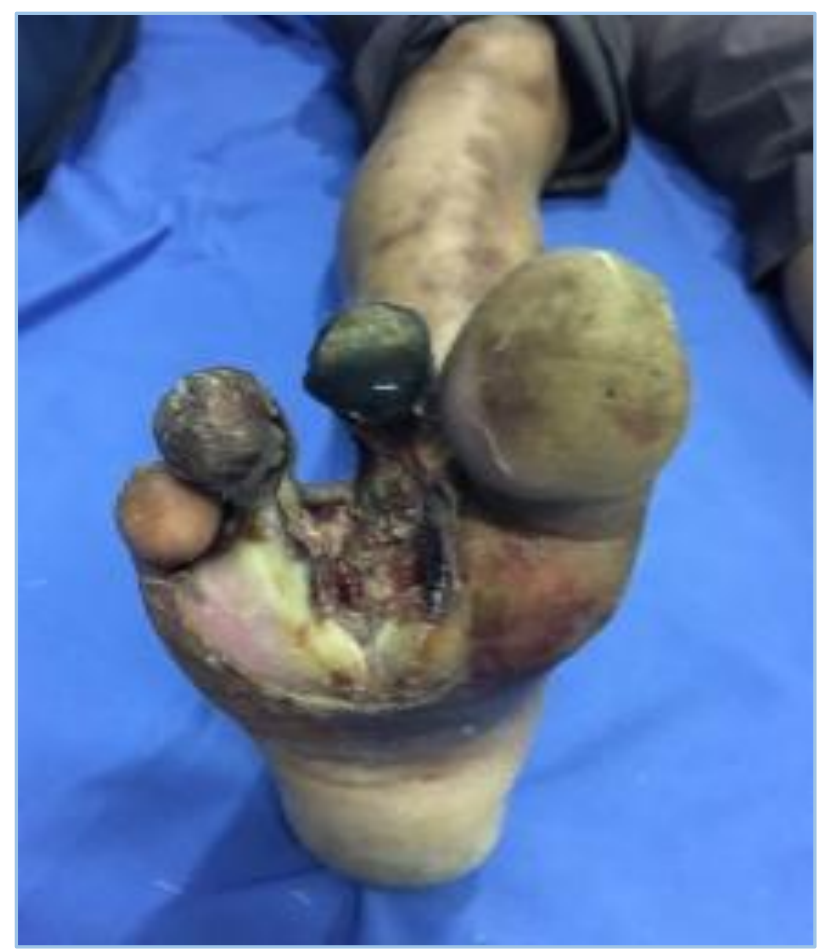

Fig. 3: Of Left Diabetic Foot. Note the Ulcer and the Gangrene. The Score for this Patient is Ulcer $2+$ Gangrene $2+$ Previous Toe amputation $2+$ Pus $4+$ Heavy Smoking 2 + P.A.D 4 + Surgeon Factor 2 = 18. Patient had Pus Tracking upto Midfoot. Patient belongs to High Risk Category for Major Amputation

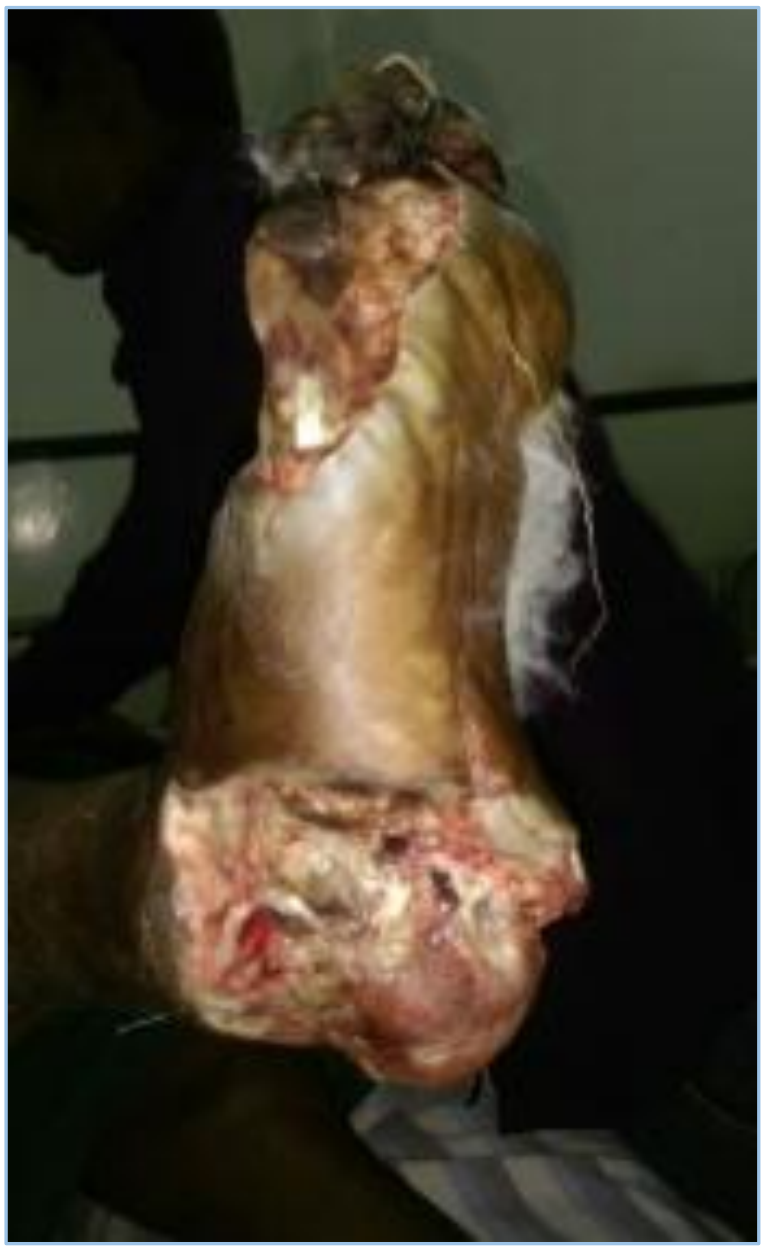

Fig. 4: Showing an Ulcer with Forefoot Gangrene who presented to our Emergency. His Score would be Ulcer 6 + pus 6 + Gangrene $2+$ Surgeon Factor $2=16$. This renders the Patient to High Risk for Major Amputation. Since Ulcer is Present both in Forefoot and Hindfoot, we took the Hindfoot Ulcer Score which is higher

\section{REFERENCES}

1. Kalaivani V, Vijayakumar HM. Diabetic foot in Indiareviewing the epidemiology and the Amit Jain's classifications. Sch Acad J Bio Sci 2013;1(6):305-308.

2. Wild S, Roglic G, Green A, et al. Global prevalence of diabetes: estimates for 2000 and projection for 2030 . Diabetes care 2004;27:1047-1053.

3. Jaykar RD, Kasabe PS, Kakani NV. Prospective study of infection of foot in diabetic patients. Int J Recent Trends Sci Tech 2014;10(2):389-395.

4. Shah SF, Hammed S, Khawaja Z, et al. Evaluation and management of diabetic foot: a multicentric study conducted at Rawalpindi, Islamabad. Ann Pak Inst Med Sci 2011;7(4):233-237.

5. Papazafiropoulou A, Tentolouris N, Soldatos RP, et al. Mortality in diabetic and non diabetic patients after amputations performed from 1996 to 2005 in a tertiary hospital population: a 3 year follow up study. J Diab Comp 2009;23:7-11.

6. Jain AKC. The new scoring system for predicting the risk of major amputations in patient with diabetic foot complication. Med-Science 2014;3(1):1068-78.

7. Alzahrni HA. Diabetes related lower extremities amputations in Saudi Arabia: the magnitude of the problem. Ann Vasc Dis 2012;5(2):151-156. 
8. Chalya PL, Mabula JB, Dass RM, et al. Major limb amputation: a tertiary hospital experience in northwestern Tanzania. J Ortho Surg Res 2012;7:18.

9. Jain AKC, Viswanath S. Studying major amputation in a developing country using Amit Jain's typing and scoring system for diabetic foot complications-time for standardization of diabetic foot practice. Int Surg J 2015;2(1):26-30.
10. Moses OM, Julius OA, Sarah NW. Diabetes related amputation in a rural African population: a rural African experience. J Diab Foot Comp 2010;2(1):6-11. 